Journal article

\title{
Putting Complex Worlds into Words - A Final Response to Prus
}

\author{
Jörg Niewöhner* Thomas Scheffer \\ 2010
}

This is the accepted manuscript (postprint) of the published journal article as follows:

Title Putting Complex Worlds into Words - A Final Response to Prus

Authors Niewöhner, Jörg; Scheffer, Thomas

Date of publication 2010

Journal

Volume

Comparative Sociology

Issue

9

4

Pages $\quad 544-547$

Publisher Brill

DOI/URL 10.1163/156913210X12555713197295 


\title{
Putting Complex Worlds into Words - A Final Response to Prus
}

\author{
Jörg Niewöhner
}

\author{
Thomas Scheffer
}

2010

This brief comment concludes the continued exchange over the notion of "thick comparison" between the original authors and Robert Prus. We are grateful to be part of such a spirited exchange of points of view and particularly thank our editor David Sciulli for providing the necessary room for this debate as well as the time to dwell on the different positions. It has been a rare and much appreciated opportunity in the frantic striving that even social science has become today.

We respond anew not because we feel it is our obligation to defend our - or for that matter - any specific approach. We respond to avoid the entanglement of our notion of "thick comparison" within a rather unhelpful debate that has often been framed as modern versus post-modern or subjectivist versus post-humanist. While this debate raises concerns that are central to social inquiry, it does not provide the most illuminating backdrop against which to understand what we mean by comparing thickly.

Hence we also do not argue for or against symbolic interactionism in one of its modern facets as so lucidly developed by Prus. In fact, most of the contributors to our endeavour are very sympathetic to Prus' position.

The key aspect of thick comparison is situated on an altogether different level: Thick comparison is not an approach. It is a problematic, neither unifying nor unified in its theoretical and methodological stance. Though it does contribute to an overall theoretical project, this project is not concerned (as is Prus) with generic social processes or the "whatness of human life." It is concerned with the role of comparison in putting complex worlds into words. As such it is reflexive and takes seriously the claim that any method necessarily represents and shapes social reality at the same time (Law 2006). As such, it is eclectic with respect to theory in Prus' sense and it is experimental with respect to method.

At its heart lies the conviction that cultural and socio-material fields do not offer themselves to ethnography, let alone ethnographic comparison. They do not offer themselves to our academic purposes, which means, they exceed any effort to pinpoint them, to order, explain, represent, model, and compare them. Thus any approach to the "complexity out there" necessarily sets a contingent cut (Barad 2007). It shapes a field and reduces its complexity while putting it into words. 
Thick comparison is not concerned with setting the most appropriate cut or building the most accurate theoretical approximation of this complexity. It is concerned with better understanding and reinvigorating the role of ethnographic comparison in the process of setting the cut and in approaching this complexity. In a second and separate step, this work may also contribute to our knowledge of generic social processes and will then have to answer and live up to, inter alia, the framework Prus unfolds in his work in such a detailed and sensitive manner.

Three commitments are central to our stance: (1) The openness for a broad range of possible theoretical approaches; (2) the utilisation of a range of types of data; and (3) the embrace of a variety of comparative standards. As a result, we are unable to commit "thick comparativists" into one shared frame of research. In order to contribute to the shared aspiration of thick comparison, we need to diversify. We need to dissociate from the premise of reductionist sciences: the explanation of all socio-material and cultural phenomena by one set of universal rules.

1. We apply eclectic theorizing that contributes to the local problem of putting complex things into words. This includes a variety of subjectivities, objectivities, and spatio-temporal relations. It also includes various modes of participation that range from anti-subjectivist thinking as in system theory, discourse analysis, or ethnomethodology to radical subjectivism as in phenomenology or rhetorics. Our theorizing moves us to the limits of concepts rather than to their cores. Our theorizing contrasts established theories rather than investing in any single framework. It is the performance, the successes and failures of different theoretical approaches understood in relation to each other that inform thick comparison as a problematic.

2. The research subjects' views and meaning-making strategies offer only one empirical source amongst others depending on perspective and field, focused productivity and socio-material or discursive mechanisms. Other types of data may include observations of body movements, the content of legal files, or the personal experience of the fieldworker. Ethnography, pushed to its methodological extreme, requires the invention of new data and new perspectives with each field. Sometimes research subjects know perfectly well what is going on; sometimes they are unable to articulate it. The range of possibilities is itself a crucial feature of the field under study. It is about the different distributions and processes of knowing and doing.

3. Standards of comparison, that is, what is seen as legitimate production of comparability, necessarily vary because fields are more or less diverse and, in addition, because they are more or less available for the analytical operations of rendering fields comparable. If we embrace and permit a variety of standards of comparison, we may also experience a variety of incomplete comparative operations. In our view, this does still matter for the ethnographic mother disciplines, including ethnology, anthropology, and today as well, sociology. What counts as failure within the rigid frameworks of most academic contexts is turned productive in thick comparison. 
It tells us how and perhaps why something is not available for comparison, how some fields undermine the tertium comparationis, or how comparison articulates inclusive and exclusive features. In allowing different standards of comparison, we are able productively to relate the resulting attempts at establishing comparability to each other.

For us, a call for diversity and modesty is closely linked to the experience of astonishing complexities "out there." The call for diversity, however, does not lead us to isolation. We engage with each other and with a variety of communities. What is more, we go on comparing "what cannot be (fully) compared" in order ultimately to re-articulate our direct or indirect experiences of complexity.

\section{References}

Barad, Karen. 2007. Meeting the Universe Halfway: Quantum Physics and the Entanglement of Matter and Meaning. Durham: Duke University Press.

Law, John. 2006. After Method, Mess in Social Science Research. Abingdon: Routledge. 